\title{
Lithium manganese oxide in an aqueous electrochemical system for low-grade thermal energy harvesting
}

\author{
Yezhou Liu ${ }^{1}$, Caitian Gao ${ }^{1}$, Soojin Sim ${ }^{1}$, Moobum Kim ${ }^{1}$, Seok Woo Lee ${ }^{1} *$ \\ ${ }^{1}$ School of Electrical and Electronic Engineering, Nanyang Technological University, \\ Singapore
}

*Corresponding author: sw.lee@ntu.edu.sg 


\section{Supporting Figures}
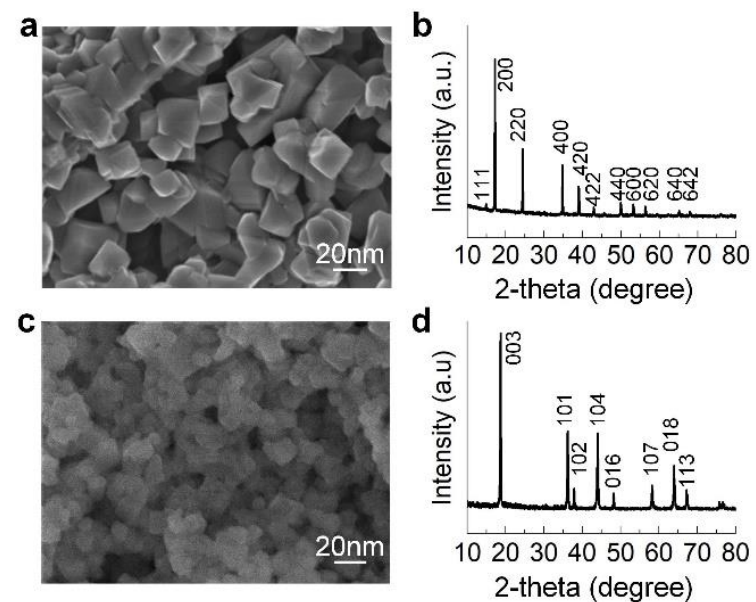

Figure S1 | Characterization of LMO and CuHCF. (a) SEM micrograph and (b) X-ray diffraction pattern of the spinel LMO (c) SEM micrograph and (d) X-ray diffraction pattern of the $\mathrm{CuHCF}$ 


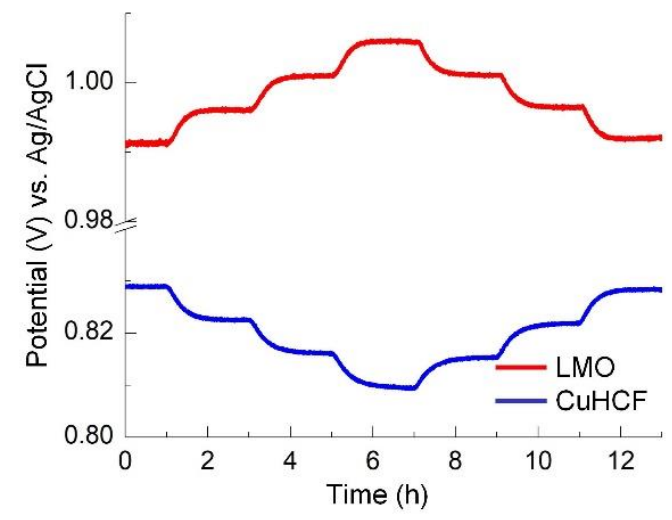

Figure S2 | Tempe rature coefficient test of LMO and CuHCF. The open circle voltage of $\mathrm{LMO}$ in $80 \%$ SOC and $\mathrm{CuHCF}$ in $50 \%$ SOC with the temperature change $10^{\circ} \mathrm{C}-20^{\circ} \mathrm{C}-30^{\circ} \mathrm{C}-40^{\circ} \mathrm{C}-30^{\circ} \mathrm{C}-20^{\circ} \mathrm{C}-10^{\circ} \mathrm{C}$. The electrolyte is $3 \mathrm{M} \mathrm{LiNO}_{3}$ and $1 \mathrm{M} \mathrm{KNO}_{3}$ aqueous electrolyte.

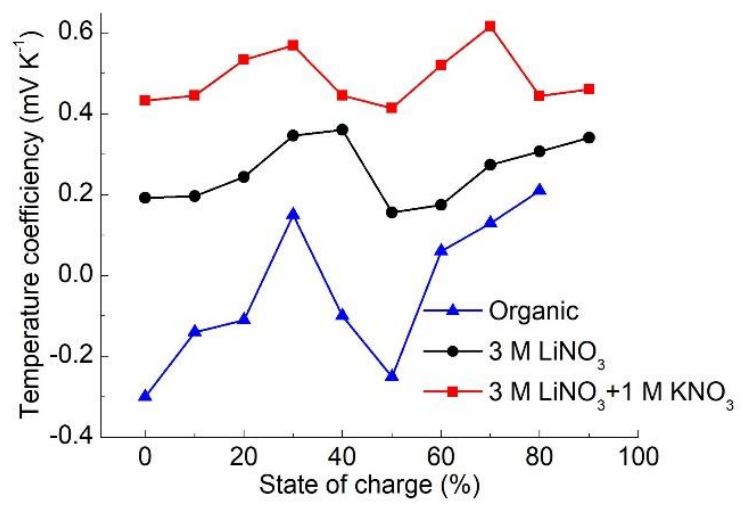

Figure S3 | Te mperature coefficient of LMO in different electroly te. Blue line is in $1.0 \mathrm{M}$ $\mathrm{LiPF}_{6}$ in EC/DMC $1: 1(\mathrm{v}: \mathrm{v})$ organic electrolyte ${ }^{1}$. Black line is in $3 \mathrm{M} \mathrm{LiNO}_{3}$ aqueous electrolyte. Red line is in $3 \mathrm{M} \mathrm{LiNO}_{3}$ and $1 \mathrm{M} \mathrm{KNO}_{3}$ aqueous electrolyte. 


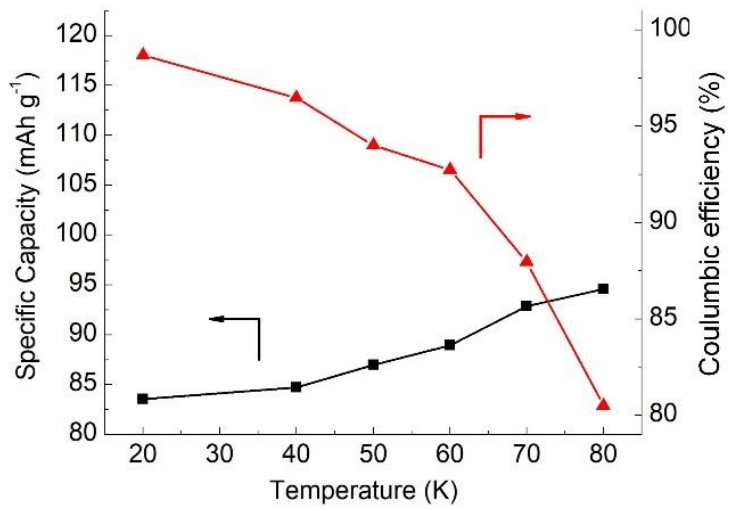

Figure S4 | Stability of LMO in diffe rent temperature. Specific capacity and coulombic efficiency are tested in different temperature. The stability increases with raising temperature. 


\section{Calculation of the efficiency}

$$
\eta=\frac{W}{Q_{H}+Q_{H R}}=\frac{W_{H}-W_{L}}{\alpha_{\text {cell }} T_{H} Q_{c}+\left(1-\eta_{H R}\right) C_{p} \Delta T}
$$

Where $\mathrm{W}$ is the net work. $Q_{\mathrm{H}}$ is the heat absorbed at $T_{\mathrm{H}} \cdot Q_{\mathrm{HR}}$ is the external heat to rise the temperature of the system to $T_{\mathrm{H}}$. $W_{\mathrm{H}}$ is the energy discharged in $T_{\mathrm{H}} . W_{\mathrm{L}}$ is the energy charged in $T_{\mathrm{L}} . \alpha_{\mathrm{cell}}$ is the temperature coefficient of the full cell. $Q_{\mathrm{C}}$ is the charge capacity of the system. $C_{\mathrm{p}}$ is the heat capacity of the system. $\eta_{\mathrm{HR}}$ is the efficiency of the heat recuperation. $\Delta T$ is the temperature differential between $T_{\mathrm{H}}$ and $T_{\mathrm{L}}^{2}$.

Heat capacity for full cell

$\mathrm{C}_{\mathrm{p}_{-} \text {full }}=\left(\mathrm{C}_{\mathrm{p}_{-} \mathrm{LMO}} * \mathrm{~m}_{\mathrm{LMO}}+\mathrm{C}_{\mathrm{p}_{-} \mathrm{CuHCF}} * \mathrm{~m}_{\mathrm{CuHCF}}\right) /\left(\mathrm{m}_{\mathrm{LMO}}+\mathrm{m}_{\mathrm{CuHCF}}\right)$

$=(0.80 * 1.7872+1.13 * 2.8899) /(1.7872+2.8899)=1.0039$

Assume $\eta_{H X}=0$

$\left(1-\eta_{H X}\right) C_{P} \Delta T=1.00 * 40=40 \mathrm{~J} \mathrm{~g}^{-1}$

Assume $\eta_{H X}=50 \%$

$$
\left(1-\eta_{H X}\right) C_{P} \Delta T=0.5 * 40=20 \mathrm{~J} \mathrm{~g}^{-1}
$$

$\alpha \mathrm{T}_{\mathrm{H}}=0.9715 * 313.15 * 0.001=0.292$

Carnot efficiency and relative efficiency

$\eta_{\text {Carnot }}=1-\frac{T_{L}}{T_{H}}=1-\frac{283}{313}=9.6 \%$ 


$$
\begin{aligned}
& \eta_{\mathrm{r}}=\frac{\eta}{\eta_{\text {Carnot }}}=\frac{1.8}{9.6}=18.8 \% \\
& \eta_{\mathrm{r}}{ }^{\prime}=\frac{\eta^{\prime}}{\eta_{\text {Carnot }}}=\frac{2.6}{9.6}=27.1 \%
\end{aligned}
$$

\section{References}

1. Yazami, R.; Reynier, Y.; Fultz, B., Entropymetry of Lithium Intercalation in Spinel Manganese Oxide: Effect of Lithium Stoichiometry. In ECS Transactions, 2006; pp 87-96.

2. Yang, Y.; Loomis, J.; Ghasemi, H.; Lee, S. W.; Wang, Y. J.; Cui, Y.; Chen, G., Membrane-free battery for harvesting low-grade thermal energy. Nano Lett 2014, 14 (11), 6578-83. 